Article

\title{
Technology for 3D System Integration for Flexible Wireless Biomedical Applications
}

\author{
Wen-Cheng Kuo * (iD) and Chih-Wei Huang \\ Department of Mechanical and Automation Engineering, National Kaohsiung University of Science and \\ Technology, 2 Jhuoyue Rd., Nanzih, Kaohsiung 811, Taiwan; u0514803@nkfust.edu.tw \\ * Correspondence: rkuo@nkfust.edu.tw; Tel.: +886-7-601-1000; Fax: +886-7-601-1066
}

Received: 16 March 2018; Accepted: 27 April 2018; Published: 2 May 2018

\begin{abstract}
This paper presents a new 3D bottom-up packing technology for integrating a chip, an induction coil, and interconnections for flexible wireless biomedical applications. Parylene was used as a flexible substrate for the bottom-up embedding of the chip, insulation layer, interconnection, and inductors to form a flexible wireless biomedical microsystem. The system can be implanted on or inside the human body. A 50- $\mu$ m gold foil deposited through laser micromachining by using a picosecond laser was used as an inductor to yield a higher quality factor than that yielded by thickness-increasing methods such as the fold-and-bond method or thick-metal electroplating method at the operation frequency of $1 \mathrm{MHz}$. For system integration, parylene was used as a flexible substrate, and the contact pads and connections between the coil and chip were generated using gold deposition. The advantage of the proposed process can integrate the chip and coil vertically to generate a single biocompatible system in order to reduce required area. The proposed system entails the use of $3 \mathrm{D}$ integrated circuit packaging concepts to integrate the chip and coil. The results validated the feasibility of this technology.
\end{abstract}

Keywords: parylene; 3D package; biomedical system; MEMS

\section{Introduction}

A growing trend is observed in the minimization of device size and the integration of various components into a single device. The chip-embedded flexible packaging technology is required to obtain small, rapid, and reliable devices. Flexible packaging entails vertically integrating the active and passive components on a flexible substrate to reduce the required area.

Previously, pieces of medical inspection equipment were considerably large and could not appropriately detect diseases without being in contact with human bodies. An implantable wireless bio-microsystem was then developed to satisfy medical requirements. Schnakenberg et al. [1] proposed an intravascular pressure monitoring system with parylene- $\mathrm{C}$ coating for monitoring blood pressure in hypertensive diseases or pulse rate in arrhythmia. Coosemans et al. [2] proposed an autonomous bladder pressure monitoring system, which registers and wirelessly transmits the bladder pressure to the doctor. Li et al. [3] proposed an integrated flexible ocular coil for power and data transfer in retinal prostheses. A parylene-based device with a gold coil could be directly integrated with multielectrode arrays and parylene-based packages incorporating application-specific integrated circuits (ASICs).

High-performance, high-density, and compact electronic products have been developed not only for portable electronic devices [4] but also for biomedical systems. In the 1990s, a system-on-chip (SoC) [5] was developed for integrating all components on a monolithic substrate to enhance the overall speed of a system and reduce power consumption. Yang et al. [6] presented a PDMS-based package with an implantable complementary metal-oxide-semiconductor (CMOS) drug delivery SoC, in which a wireless controller/actuation circuitry and a drug delivery array are monolithically integrated. Chiu et al. [7] 
proposed a pain control system with a flexible substrate, integrating a flat spiral induction coil and CMOS-based SoC. However, system efficiency is limited by the inadequate performance of a radio frequency (RF) circuit and decoupling capacitors due to size constrains. To overcome this limitation, Chang et al. [8] proposed a three-coil wireless power transfer system using a 3D package. However, the integration of chips and passive components in high-density electronic devices also satisfies both size and performance requirements. The 3D package [9] was used to satisfy both requirements.

Initially, system-in-package (SiP) technology was used to develop 3D packaging by using wire bonding [10] and a solder ball [11], integrating all the components along the Z-axis. For example, Chandler [12] integrated an optoelectronic and radio subsystem by using a 3D SiP process, which reduced the weight, area, and cost of the system. Yole Inc. [13] proposed a wafer-level packaging/3D IC through silicon via by using deep reactive ion etching (DRIE) or laser drilling to create the via and interconnection techniques and reduce the interconnection length in order to improve the performance. This technique could integrate different chips into a system, including RF, logic circuit, and micro-electro-mechanical system (MEMS) devices. Solid materials, such as silicon and printed circuit board (PCB), were used as substrates. Berenyi et al. [14] used polyimide (PI) as a substrate and then employed ultraviolet laser cutting and integrated five IC chips on the flexible PI substrate for reducing the area by $55 \%$ without causing the overheating problem. In this study, interconnections were imbedded with microvoids by using the 3D IC process, and the chip and coil were integrated using the SiP process to reduce the area.

The bio-implantable systems were used in batteryless implantable CMOS SoC [7] and retinal prostheses [3]. A wireless bio-implantable system should be biocompatible, which engenders a problem. The materials to be used must be nontoxic, nonthrombogenic, noncarcinogenic, and nonirritant [15]. Gold and parylene are biocompatible materials of United States Pharmacopeia (USP)-VI grade, which can be used for implantable systems [16]. In such systems, parylene can serve as a flexible substrate to form conformal coatings for gold-based interconnections and chips to integrate the chips and induction coils into a system. In this work, a silicon substrate was used as a mold to create a trench for chip embedding and deposit/pattern gold as an interconnection between conduction pads, and a coil was then pasted on the interconnection. Parylene deposited between the coil and interconnections was considered as an insulation layer and capsulation. When the capsulation was completed, the silicon substrate could be removed from the system after dicing.

\section{Design}

\subsection{Theory of Induction Coils}

An induction coil is used for energy and signal communication inside a wireless microsystem. The Q-factor is used for determining quality [17], which can be calculated as follows:

$$
Q=\frac{\omega L_{s}}{R_{s}}\left[1-\left(\frac{\omega}{\omega_{r}}\right)^{2}\right]
$$

where $L_{S}$ and $R_{S}$ are the inductance and resistance, respectively. $\omega$ and $\omega_{r}$ are the operating and resonant frequencies of the inductor, respectively. Based on (1), the inductor must be operated below self-resonance to avoid the minimization of the Q-factor incurred by the loss of self-resonance.

O'Driscoll [18], Sauer [19], and Vaillancour [20] have revealed that the energy loss decreased for a frequency ranging from 1 to $10 \mathrm{MHz}$. Flexible inductors are commonly used in implantable biomedical devices to wirelessly transmit energy and data. However, the device size and operational frequency (approximately $1 \mathrm{MHz}$ ) [7] used for energy transmission limits the quality factor (Q-factor) when coupling with external circuits [21].

In this paper, $50 \mu \mathrm{m}$ of gold was used by micro-laser machining to enhanced the Q-factor at $1 \mathrm{MHz}$ because of the skin effect, thereby reducing the corresponding resistance of the inductor [22] to replace the time consuming fold-and-bond [23] and thick-metal electroplating methods [24]. 


\subsection{Dummy Chip Experiment}

This study integrated a high-Q inductor and an energy-harvesting chip into a wireless microsystem. The system required an SoC to integrate the logic components into a chip. To make the process feasible, a dummy chip with the same size as an energy-harvesting chip ( $4 \mathrm{~mm} \times 3 \mathrm{~mm}$ ) was used. Moreover, the same RF input/output pads ( $80 \mu \mathrm{m} \times 80 \mu \mathrm{m}$, spacing $21 \mu \mathrm{m})$ were used. In the designed dummy chip, for electricity conduction throughout the system, the two RF I/O pads were one interval between adjacent connected using gold interconnection, as shown in Figure 1. The height of the dummy chip is $250 \mu \mathrm{m}$ without thinning process.

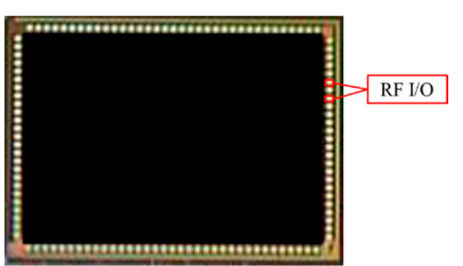

(a)

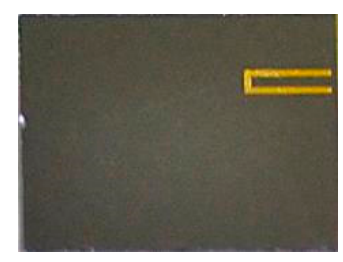

(b)

Figure 1. Contact pad position for actual energy-harvesting chip (a) and dummy chip (b).

\subsection{D Packaging Process Design}

This study proposes a new 3D bottom-up packing technology for chips, induction coils, and interconnections. Parylene was used as the flexible substrate for bottom-up embedding of the chip, insulation layer, interconnection, and inductors to create a flexible wireless biomedical microsystem. A silicon wafer was used to integrate the chip and parylene substrate. The trench was etched using inductively coupled plasma (ICP)-DRIE to fit the chip and parylene. ICP-DRIE could be used to etch the precise depth required for the chip and parylene substrate. The dump chip, combined with the aligned key in the silicon wafer, can fit the trench by aligning the $\mathrm{X}_{-}, \mathrm{Y}_{-}$, and $\mathrm{Z}$-axes. A parylene insulation layer was deposited between the metal connections for insulation, and reactive ion etching (RIE) was used for opening the parylene insulation layer under the connection pad. Gold was then deposited inside the opening to create vias between metal layers. The design concept is presented in Figure 2.

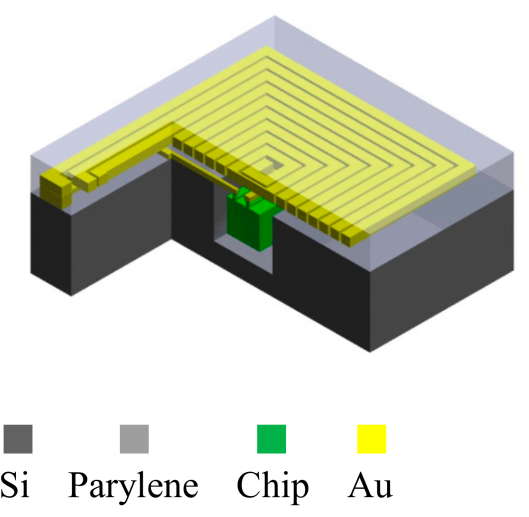

Figure 2. Cross-section of the wireless biomedical microsystem.

\section{Fabrication}

\subsection{Induction Coil Fabrication}

The induction coil was fabricated with the technology used in [22]. Parylene-C was used as the polymer substrate, and the coil was patterned using a pulsed laser, as shown in Figure 3. 
Compared with the fold-and-bond [23] and thick-metal electroplating [24] process, the proposed process can easily and rapidly generate an induction coil with a larger thickness and higher quality factor. The proposed process can be used for fabricating an implantable bio-microsystem for energy and signal communication.

(a) Au foil

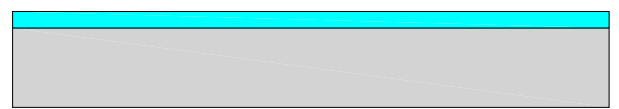

(b) Spin on the photoresist

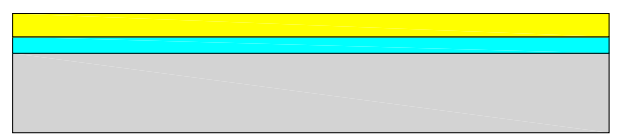

(c) Pasting the Au foil on the photoresist

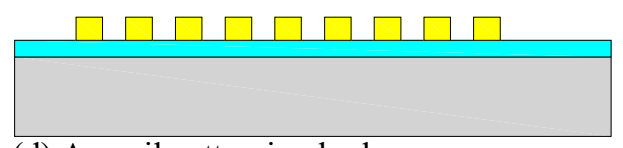

(d) Au coil patterning by laser

micromachining

(e) Peel off the substrate

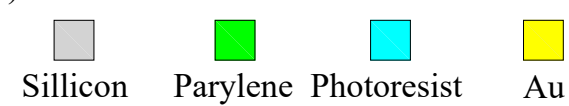

Figure 3. Process of coil fabrication through laser micromachining.

\subsection{Induction Coil and Chip Integration}

The 3D bottom-up integration process of the chip is shown in Figure 4. The process is as follows: Step a: ICP etching

Photoresist AZ4620 with a thickness of approximately $15 \mu \mathrm{m}$ was spun on a silicon wafer as an etching mask, and ICP silicon etching was used for deep silicon etching $(250 \mu \mathrm{m})$.

Step b: Parylene coating

$30 \mu \mathrm{m}$ of parylene was deposited on the wafer as a flexible substrate.

Step c: Chip embedding

The sample was heated up to $80^{\circ} \mathrm{C}$ and the chip was embedded.

Step d: First parylene package

After the chip was embedded, parylene measuring $2 \mu \mathrm{m}$ was deposited as the first isolation layer. Step e: Photoresist patterning

Photoresist AZ4620 of approximately $5 \mu \mathrm{m}$ thickness was spun on the parylene base as the etching mask, followed by a pattern transfer process. Concerning the thickness variation of parylene before and after baking, the temperature of soft and hard bake is $80^{\circ} \mathrm{C}$, which is smaller and close to the glass transition point $\left(80-100^{\circ} \mathrm{C}\right)$ of parylene $\mathrm{C}$, and the linear coefficient of expansion is about $3.8 \times 10^{-5} /{ }^{\circ} \mathrm{C}$. The thickness variation before and after baking is small. 
Step f: First parylene etched using RIE

Parylene was etched using RIE. The pad on the chip was then exposed for via patterning. The AZ4620 will be removed after etching.

Step g: First gold deposition

Gold (2000 ̊̊) was deposited using an electron beam evaporator as the interconnection layer.

Step h: Photoresist patterning

Photoresist S1818 of approximately $2 \mu \mathrm{m}$ thickness was spun on the gold base as the etching mask for via patterning, followed by a pattern transfer process.

Step i: First gold etching

Gold wet etching was used for the etchant solution, and gold was patterned for the conductive wire.

Step j: Second parylene package

After gold etching, parylene measuring $2 \mu \mathrm{m}$ was deposited as the second isolation layer.

Step k: Photoresist patterning

Photoresist AZ4620 of approximately $5 \mu \mathrm{m}$ thickness was spun on the parylene base as the etching mask, followed by a pattern transfer process.

Step 1: Second parylene etched by RIE

Parylene was etched using RIE. The parylene hole was then used for depositing the interconnection metal.

Step m: Second gold deposition

Gold (2000 ̊̊) was again deposited using the E-beam evaporator as the interconnection layer.

Step n: Photoresist patterning

Photoresist S1818 of approximately $2 \mu \mathrm{m}$ thickness was spun on the second gold base as the etching mask, followed by a pattern transfer process.

Step o: Second gold etching

Gold wet etching was used for the etchant solution and the second gold was patterned for the interconnection pad. Figure 5 shows the close look of the second interconnection pad in step 0 . The second interconnection pad is $1500 \mu \mathrm{m} \times 1500 \mu \mathrm{m}$ for gold coil pasting.

Step p: Gold foil pasting

A gold coil of approximately $50 \mu \mathrm{m}$ thickness was pasted on the interconnection pad by using hot embossing after the gold foil was patterned using the pulse laser.

Step q: Third parylene package

A third layer of parylene measuring $30 \mu \mathrm{m}$ in thickness was deposited, and all elements were packaged. 
Step r: Wafer removal

More than $60 \mu \mathrm{m}$ thickness of parylene has adequate stiffness that the system can be peeled off directly from the silicon wafer and a flexible microsystem was obtained.
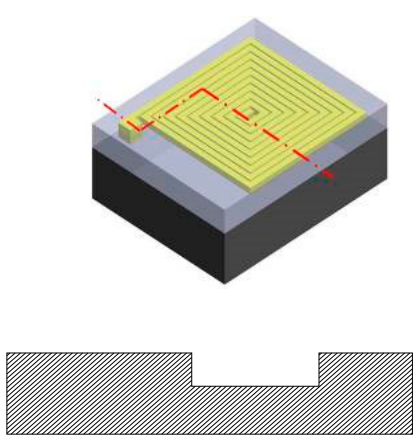

(a) ICP etching

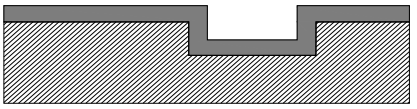

(b) Parylene base coating

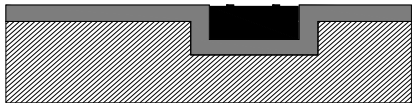

(c) Chip embedding

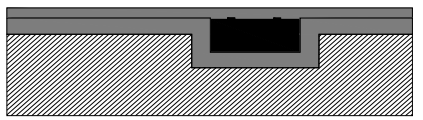

(d) 1st Parylene package

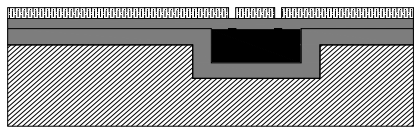

(e) Photoresist patterning

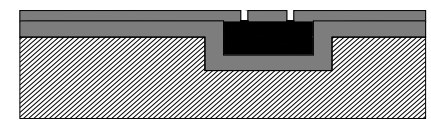

(f) 1 st Parylene etched by RIE

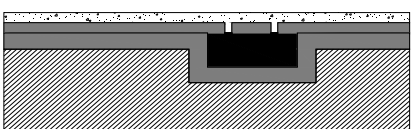

(g) 1 st Au deposition

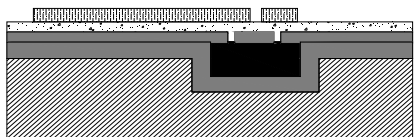

(h) Photoresist patterning

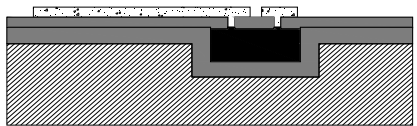

(i) $1 \mathrm{st} \mathrm{Au} \mathrm{etching}$
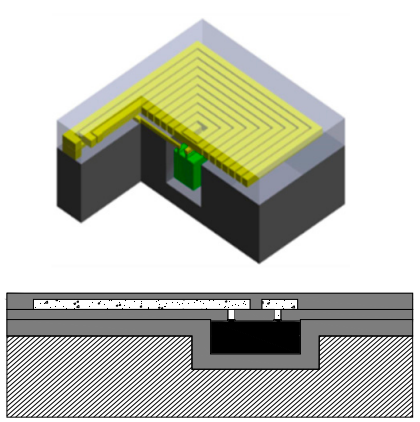

(j) 2nd Parylene package

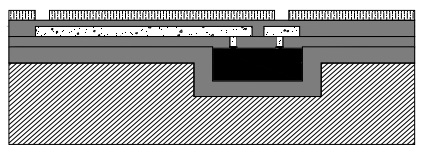

(k) Photoresist patterning

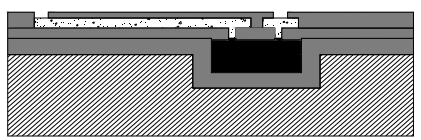

(1) 2nd Parylene etched by RIE

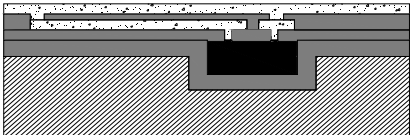

(m) 2nd Au deposition

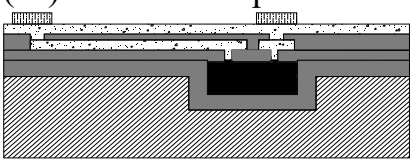

(n) Photoresist patterning

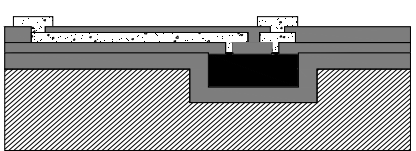

(o) 2nd Au etching

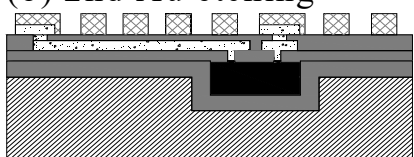

(p) Au coil pasting

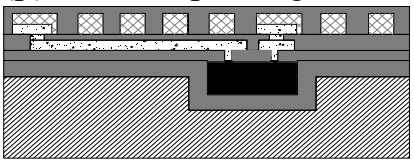

(q) 3 rd Parylene package

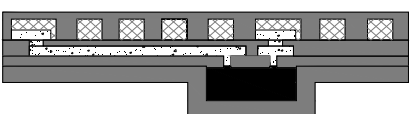

(r) Wafer removal

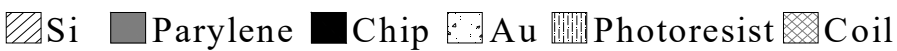

Figure 4. Fabrication process for system integration. 

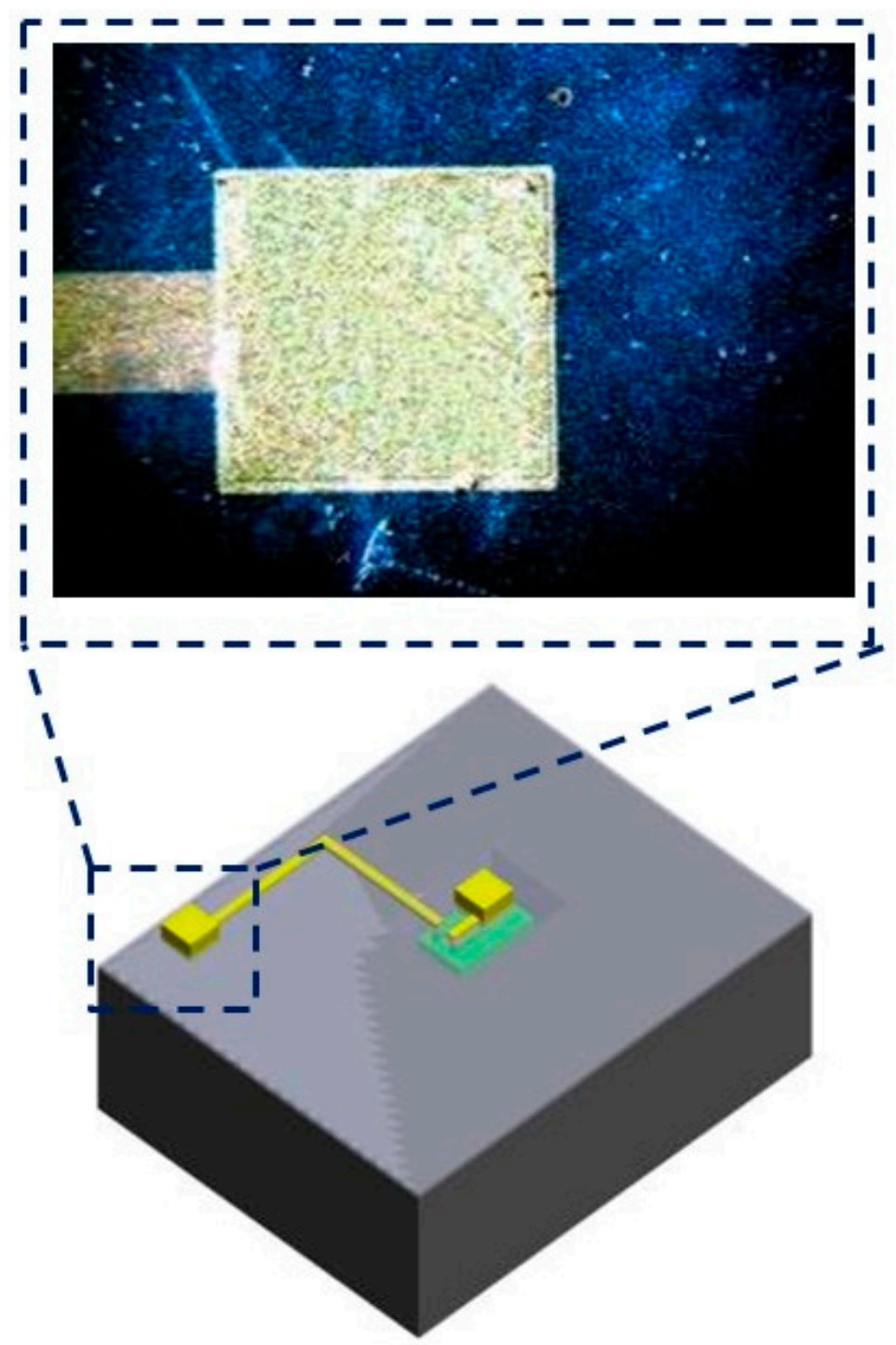

Figure 5. The close view of the second interconnection pad in step o. The second interconnection pad is $1500 \mu \mathrm{m} \times 1500 \mu \mathrm{m}$ for Au coil pasting. There is a $60 \mu \mathrm{m}$ of the overlap area can accommodate the misalignment.

Concerning the misalignments during the chip integration, $\mathrm{X}$ and $\mathrm{Y}$ axis misalignments of chip comes from the silicon trench etching and chip dicing. To overcome the misalignments, the patterns of via opening are larger than the pads of chip to accommodate the $X$ and $Y$ misalignments in step $f$ shown in Figure 6. The $\mathrm{Z}$ axis of misalignment comes from the deviation of etching depth, and parylene has the excellent conformal deposition and trench filling capability, the discrepancy between IC and substrate can be larger than $2 \mu \mathrm{m}$. However, the conformal deposition capability of photoresist is poor than parylene, the discrepancy capability is limited by photoresist. $5 \mu \mathrm{m}$ of AZ4620 was spun on the parylene, so the discrepancy (Z-axis misalignment) between IC and parylene is less than $5 \mu \mathrm{m}$. 


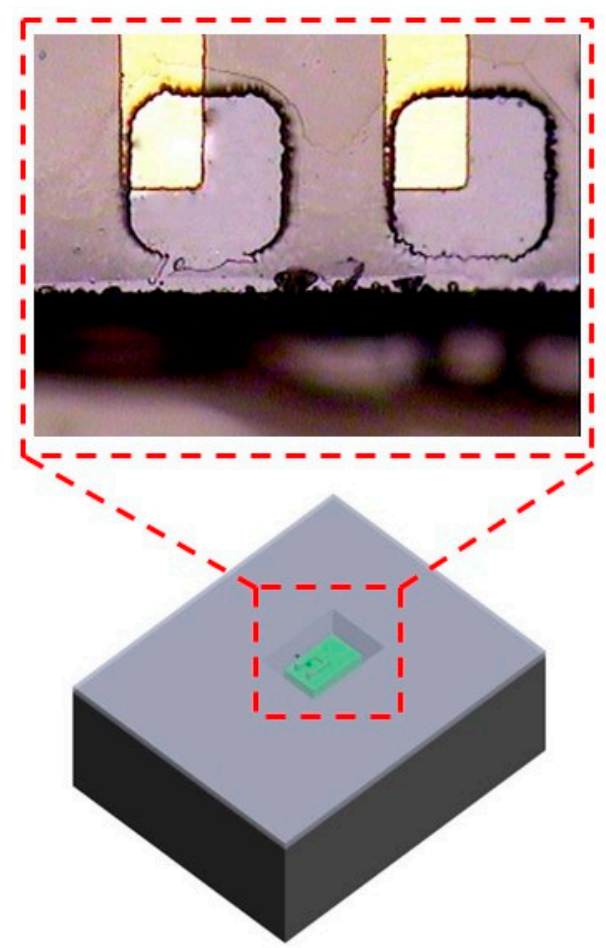

Figure 6. The patterns of via opening are larger than the pads of chip to accommodate the $X$ and $Y$ misalignments in step $\mathrm{f}$.

\section{Measurement Setup}

When the coil was pasted on the system and the interconnection was completed before the uppermost parylene layer was covered, an Agilent 4294A impedance analyzer was used along with an Agilent 166334A probe to measure the inductance and resistance. Figure 7 illustrates the measurement setup involving the use of a probe to measure the pads of coils. The inductance and resistance of the system were acquired, and the Q-factor was calculated using (1).

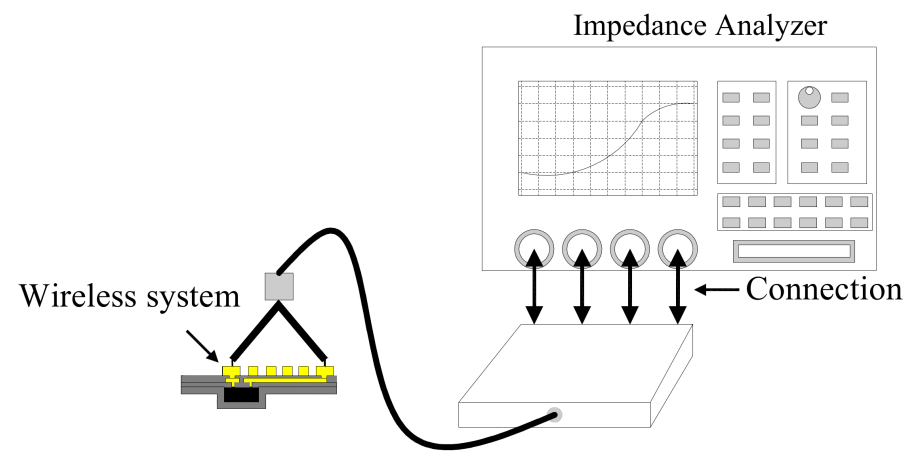

Figure 7. Inductance and resistance measurements.

\section{Results and Discussion}

\subsection{Patterned Coil}

A gold coil of $50 \mu \mathrm{m}$ thickness was created using a pulsed layer [24]. The coil specifications are shown in Table 1, and Figure 8 presents the machined coil produced using laser cutting. 
Table 1. Specifications of coil design.

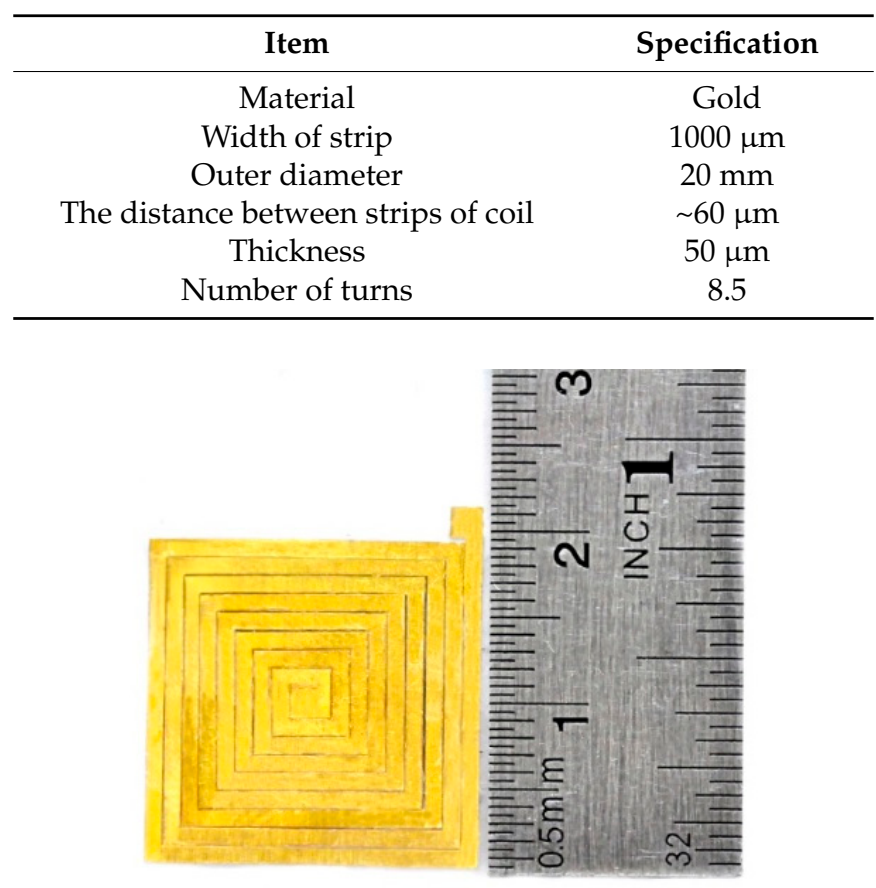

Figure 8. Laser-micromachined coil fabricated through laser cutting.

\subsection{Wireless Microsystem}

The wireless microsystem was finished using the proposed process shown in Figure 4. Figures 9 and 10 display the front and back views of the flexible wireless system, respectively. Table 2 shows the measurement results for the coil and the system at the operating frequency of $1 \mathrm{MHz}$. The Q-factor of the system was approximately 4.27 .

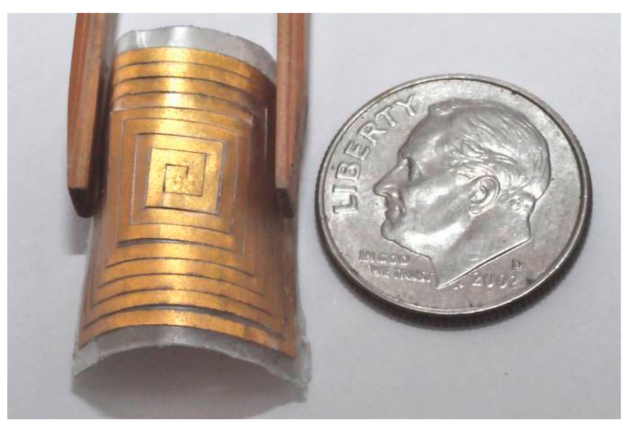

Figure 9. Front view of flexible wireless biomedical system.

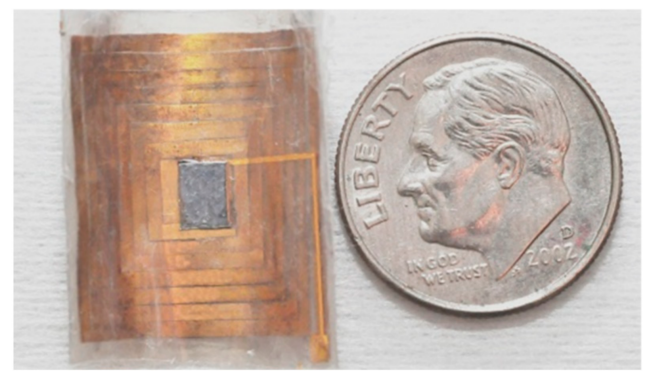

Figure 10. Back view of flexible wireless biomedical system. 
Table 2. Measurement results for the coil and the system at an operating frequency of $1 \mathrm{MHz}$.

\begin{tabular}{cccc}
\hline Item & Inductance $(\mathbf{n H})$ & Resistance $(\mathbf{m} \Omega)$ & Q-Factor \\
\hline Induction coil & 600 & 570.24 & 6.61 \\
Induction coil with system & 557 & 819.15 & 4.27 \\
\hline
\end{tabular}

\section{Conclusions}

This study presents a new 3D bottom-up packaging technology, which reduces the chip area without degrading performance. Parylene was used in this study as a flexible substrate for bottom-up embedding of a chip, insulation layer, interconnection, and inductors to create a flexible wireless biomedical microsystem. Because parylene and gold are bio-implantable materials of USP-VI grade, the entire wireless microsystem can be implanted on or inside the human body. A dummy chip was developed, and the measurement results indicate that at an operating frequency of $1 \mathrm{MHz}$, the Q-factor of the system was approximately 4.27 .

Author Contributions: W.-C.K. and C.-W.H. conceived and designed the experiments; C.-W.H. performed the experiments; W.-C.K. and C.-W.H. analyzed the data; W.-C.K. wrote the paper.

Acknowledgments: This work was supported by the National Science Council, Taiwan, under award number MOST 105-2221-E-327-029 and MOST 106-2221-E-327-020.

Conflicts of Interest: The authors declare no conflict of interest.

\section{References}

1. Schnakenberg, U.; Krüger, C.; Pfeffer, J.G.; Mokwa, W.; vom Bögel, G.; Günther, R.; Schmitz-Rode, T. Intravascular pressure monitoring system. Sens. Actuators A 2004, 100, 61-67. [CrossRef]

2. Coosemans, J.; Puers, R. An autonomous bladder pressure monitoring system. Sens. Actuators A 2005, 123-124, 155-161. [CrossRef]

3. Li, W.; Rodger, D.C.; Weiland, J.D.; Humayun, M.S.; Tai, Y.C. Integrated flexible ocular coil for power and data transfer in retinal prostheses. In Proceedings of the 27th Annual Conference of the IEEE Engineering in Medicine and Biology, Shanghai, China, 1-4 September 2005; pp. 1028-1031.

4. Tummala, R.R.; Swaminathan, M. Introduction to System-on-Package (SOP); McGraw-Hill: New York, NY, USA, 2008; pp. 3-23.

5. Pavlidis, V.F.; Friedman, E.G. Three-Dimensional Integrated Circuit Design; Elsevier Inc.: New York, NY, USA, 2009; pp. 17-36.

6. Yang, Y.J.; Huang, Y.J.; Liao, H.H.; Wang, T.; Huang, P.L.; Lin, C.W.; Wang, Y.H.; Lu, S.S. A release-on-demand wireless CMOS drug delivery SoC based on electrothermal activation technique. In Proceedings of the IEEE International Solid-State Circuits Conference, Taipei, Taiwan, 10 February 2009; pp. 288-290.

7. Chiu, H.W.; Lin, M.L.; Lin, C.W.; Ho, I.H.; Lin, W.T.; Fang, P.H.; Lee, Y.C.; Wen, Y.R.; Lu, S.S. Pain Control On Demand Based on Pulsed Radio-Frequency Stimulation of the Dorsal Root Ganglion Using a Batteryless Implantable CMOS SoC. IEEE Trans. Biomed. Circuits Syst. 2010, 4, 350-359. [CrossRef] [PubMed]

8. Chang, J.H.C.; Liu, Y.; Kang, D.; Monge, M.; Zhao, Y.; Yu, C.C.; Emami-Neyestanak, A.; Weiland, J.; Yun, M.H.; Tai, Y.C. Packaging Study for a 512-Channel Intraocular Epiretinal Implant. In Proceedings of the IEEE MEMS Conference, Taipei, Taiwan, 20-24 January 2013; pp. 1046-1048.

9. Yole Development. 3DIC E TSV Report: Cost, Technologies \& Markets; Yole Development: Lyon, France, 2007.

10. Karnezos, M. 3-D Packaging: Where All Technologies Come Together. In Proceedings of the IEEE/SEMI International Electronics Manufacturing Technology Symposium, San Jose, CA, USA, 14-16 July 2004; pp. 64-67.

11. Miettinen, J.; Mantysalo, M.; Kaija, K.; Ristolainen, E.O. System Design Issues for 3D System-in-Package (SiP). In Proceedings of the IEEE International Electronic Components and Technology Conference, Las Vegas, NV, USA, 4 June 2004; pp. 610-615. 
12. Faure, C.; Val, A.; Couderc, P.; Chandler, N.; Preziosi, E.; Ousten, Y. 3D system-inpackage: Technology improvements for volume manufacturing. In Proceedings of the IMAPS MicroTech, Cambridge, UK, 7-8 March 2006.

13. Eloy, J.C. Market Trends E Cost Analysis for 3D ICs; Yole Development: Lyon, France, 2007.

14. Berenyi, R. Prototyping of a reliable 3D flexible IC cube package by laser micromachining. Microelectron. Reliab. 2009, 49, 800-805. [CrossRef]

15. Williams, D.F. On the mechanisms of biocompatibility. Biomaterials 2008, 29, 2941-2953. [CrossRef] [PubMed]

16. Rodger, D.C.; Weiland, J.D.; Humayunb, M.S.; Tai, Y.C. Scalable high lead-count parylene package for retinal prostheses. Sens. Actuators B 2006, 117, 107-114. [CrossRef]

17. Yue, C.P.; Wong, S.S. On-Chip Spiral Inductors with Patterned Ground Shields for Si-Based RF IC's. Solid-State Circuits 1998, 33, 743-752. [CrossRef]

18. O’Driscoll, S.; Poon, A.S.Y.; Meng, T.H. A mm-Sized Implantable Power Receiver with Adaptive Link Compensation. In Proceedings of the IEEE International Solid-State Circuits Conference-Diqest of Technical Papers 2009 (ISSCC 2009), San Francisco, CA, USA, 8-12 February 2009; pp. 294-295.

19. Sauer, C.; Stanaćević, M.; Cauwenberghs, G.; Thakor, N. Power Harvesting and Telemetry in CMOS for Implanted Devices. IEEE Trans. Circuits Syst. I Regul. Pap. 2005, 52, 2605-2613. [CrossRef]

20. Vaillancourt, P.; Djemouai, A.; Harvey, J.F.; Sawan, M. EM Radiation Behavior upon Biological Tissues in a Radio-Frequency Power Transfer Link for a Cortical Visual Implant. In Proceedings of the 19th Annual International Conference of the IEEE Engineering in Medicine and Biology Society, Chicago, IL, USA, 30 October-2 November 1997; Volume 6, pp. 2499-2502.

21. Li, W.; Rodger, D.C.; Meng, E.; Weiland, J.D.; Humayun, M.S.; Tai, Y.-C. Flexible parylene packaged intraocular coil for retinal prostheses. In Proceedings of the IEEE Microtechnologies in Medicine and Biology Conference, Okinawa, Japan, 9-12 May 2006; pp. 105-108.

22. Kuo, W.-C.; Hsu, C.-Y.; Yang, Y.-J. New Fabrication Method for High-Q MEMS Inductors. In Proceedings of the ASME 2012 International Mechanical Engineering Congress \& Exposition, Houston, TX, USA, 9-15 November 2012; pp. 1-5.

23. Li, W.; Rodger, D.C.; Pinto, A.; Meng, E.; Weiland, J.D.; Humayun, M.S.; Tai, Y.-C. Parylene-based integrated wireless single-channel neurostimulator. Sens. Actuators A 2011, 166, 193-200. [CrossRef]

24. Rais-Zadeh, M.; Ayazi, F. Characterization of high-Q spiral inductors on thick insulator-on-silicon. J. Micromech. Microeng. 2005, 15, 2105-2112. [CrossRef] 